\title{
Energy saving in day-roosting female Myotis emarginatus during reproduction (Chiroptera: Vespertilionidae)
}

\section{Friederike SPITZENBERGER \& Edmund WEISS}

BatLife Österreich, Wien, Austria; friederike.spitzenberger@batlife.at

received on 16 December 2021

\begin{abstract}
From May to June 2012, we studied the behaviour of day-roosting reproductive female Geoffroy's bats in a maternity roost in eastern Burgenland (Austria) which is under surveillance from 2011 till to date. By using a remote-controlled infrared-illuminated video camera, we conducted six weekly sessions of direct observation and instantaneous scan sampling, each lasting 16 hours. Based on a total of 384 sampling sessions, we quantified the amount of time adult females spent in the activities resting, alert, grooming and relocating during pregnancy and lactation. Ambient and roost temperatures were recorded hourly, the numbers of individuals returning to the roost in the mornings were registered constantly by using an infrared light barrier. Over the entire study period, all bats arriving in the maternity roost in the morning formed immediately a single huddling cluster. As a rule, this cluster was large, multilayered, three-dimensional and tight. It did not change in size and form until the onset of pre-emergence activities. It consisted of an interior part in which about $50 \%$ of all bats roosted and the periphery consisting of those bats which had not succeeded in entering the interior. Over the entire diurnal stay in the roost, resting - which causes the least energy output - was the predominant behaviour of all roost mates. Significant differences were found, however, in the amount of time allocated to some activities by bats occupying different positions in the cluster. While bats in the interior of the cluster spent the estimated $90-95 \%$ of the entire day-roosting period resting, bats on the periphery spent only $57-73 \%$ resting. The average percentage of time allocated by peripheral bats to grooming decreased from $27 \%$ in the first week to $19-13 \%$ in the following weeks of pregnancy and stayed at $16 \%$ during the two weeks of lactation. The mean percentages of being alert and of relocating ranged between $7-10 \%$ and $4-7 \%$, respectively. During the last two weeks of pregnancy and the two weeks of lactation, roost temperatures, daily colony size and reproductive states did not influence the huddling behaviour significantly. However, activities performed in the first and second week were probably influenced by unrest due to colony formation after the return from hibernation (week 1) and by cold ambient temperatures during the week 2. Our study supports the hypothesis that the short duration and notable timing of reproduction typical for Myotis emarginatus (SPITZENBERGER \& Weiss 2020) is achieved by maximal energy saving through continuous huddling in a large, three-dimensional, multilayered and tight cluster over both the entire day-roosting and entire reproductive period, differences in the behaviours of bats located in the interior and on the periphery of the cluster and lack of social interactions between roost mates.
\end{abstract}

Key words. Myotis emarginatus, maternity roost, time budget, social thermoregulation.

\section{INTRODUCTION}

The annual cycle of bats living in temperate zones is divided into an active and an inactive period. This forces bat species to make a trade off between maintenance attained during 
day-roosting and hibernation and reproduction which is energetically very costly for females. During cold temperatures and low prey abundance which impose high energetic costs, reproductive females commonly save energy by using torpor, but this may reduce the rates of foetal (RACEY 1973) and juvenile (WILDE et al. 1999) development and prolong the time spent in the maternity roost. Another strategy of energy conservation is social thermoregulation by tight clustering in groups in a suitably tempered maternity roost (TRUNE \& SLOBODCHIKOFF 1976, HAYES et al. 1992, BoYLes et al. 2008). Huddling provides substantial energy savings and is estimated to reduce energy expenditure by between 6\% and 53\%. (GILBERT et al. 2010).

The Geoffroy's bat, Myotis emarginatus (Geoffroy, 1806), can serve as a model for achieving a very long hibernation period by keeping reproduction short and regularly timed despite the occurrence of inclement weather spells (SPITZENBERGER \& WeISS 2020). We hypothesise that roosting in a bee-swarm-like huddling cluster as exercised by day-roosting females in the maternity roost is a highly developed energy saving method that enables Geoffroy's bats to shorten the reproduction period. To throw light on this question, we recorded the allocation of time to various diurnal activities causing different energy expense by the maternity colony members. Although time budget analyses cannot be used to extrapolate energy costs of various activities (Voigt \& Cruz-Neto 2009), they can provide a useful basis for an estimation of the energy budgets.

\section{MATERIAL AND METHODS}

\section{Study s pecies}

Myotis emarginatus is the only European Myotis species which belongs to the Ethiopian genetic clade; it descended from ancestors that ranged across Asia and Africa, then became isolated in the Oriental region, and finally reached Europe through a range expansion (RUEDI \& MAYER 2001, RUEDI et al. 2013). Compared to other European Myotis species, it is characterised by some exceptional traits: (1) occurrence of conspicuous body markings in infants (SPITZENBERGER \& WeIss 2017); (2) a very long hibernation period (KugELSCHAFTER \& HENSLE 2017) and a correspondingly short reproduction period (RichaRZ et al. 1989 ) at the expense of reproductive output (SPITZENBERGER \& Weiss 2020); (3) annual maternity roost usage, reproductive phases, emergence and return flights, and time spent outside the roost are short and fairly regular (ZAHN et al. 2010, SPITZENBERGER \& WeISS 2020); (4) forming large huddling clusters by females during pregnancy and lactation (GAISLER 1971, HARrison \& BATES 1991, Richarz et al. 1989, ZAHN \& HENATSCH 1998).

The Geoffroy's bat is a small (body mass 7-9 g) bat. Its predominant food are spiders (BAUERoví 1986, BeCK 1995, Goitr et al. 2011) and flies hunted in cowsheds (BRINKMANn et al. 2001, STECK \& BrinKMANN 2006, ZAHN et al. 2010, KERVYN et al. 2012). M. emarginatus was originally restricted to the circum-Mediterranean region and expanded northwards to the Netherlands and Poland during the last few centuries (BENDA \& HANÁK 2003, HORÁČEK \& JÓŽA 2011). In the southern parts of its distribution range, Geoffroy's bats roost all year round in caves, at higher latitudes the maternity roosts are located in lofts of buildings, swarming and hibernation takes place in caves. During reproduction, females form maternity colonies of a varying size. As not all females give birth every year, the colonies consist of reproductive and non reproductive females (SPITZENBERGER \& WeIss 2020). Males roost solitarily or in small groups away from the maternity roosts.

\section{Study site and date}

From 7 May to 12 June 2012, weekly observations of day-roosting activities carried out by pregnant and lactating female Geoffroy's bats were conducted in a loft of the castle of Lockenhaus ( $47^{\circ} 24^{\prime} \mathrm{N}, 16^{\circ} 51^{\prime} \mathrm{E}$, 
Table 1. Dates and duration of observational and scan sampling sessions

\begin{tabular}{lrrr}
\hline week & early session & late session & reproductive \\
& $03: 00-10: 00$ & $11: 00-20: 00$ & state \\
\hline 1 & 8 May 2012 & 7 May 2012 & pregnancy \\
2 & 15 May 2012 & 14 May 2012 & pregnancy \\
3 & 22 May 2012 & 21 May 2012 \\
4 & 29 May 2012 & 28 May 2012 & pregnancy \\
5 & 5 June 2012 & 4 June 2012 & lactation \\
6 & 12 June 2012 & 11 June 2012 & lactation \\
\hline
\end{tabular}

$353 \mathrm{~m}$ a. s. 1.), Burgenland, Austria. The castle is situated in the transboundary (Austrian-Hungarian) Geschriebenstein-Írrotkö Nature Park and is protected as a Natura 2000 site. The chamber in which the maternity colony roosts has only one access window. The room is $17.5 \mathrm{~m}$ long, $3 \mathrm{~m}$ wide and has a volume of ca. $200 \mathrm{~m}^{3}$. It is situated under a partly north facing and partly south-east facing roof with one access window. The roof consists of the asbestos cement (Eternit) plates. During the study period, the colony aggregated every morning in the darkest part of the room on a $2 \mathrm{~m}$ long horizontal beam which is positioned $2.4 \mathrm{~m}$ above the floor (Fig. 1). We marked the beam with numbers in $20 \mathrm{~cm}$ distance that are visible

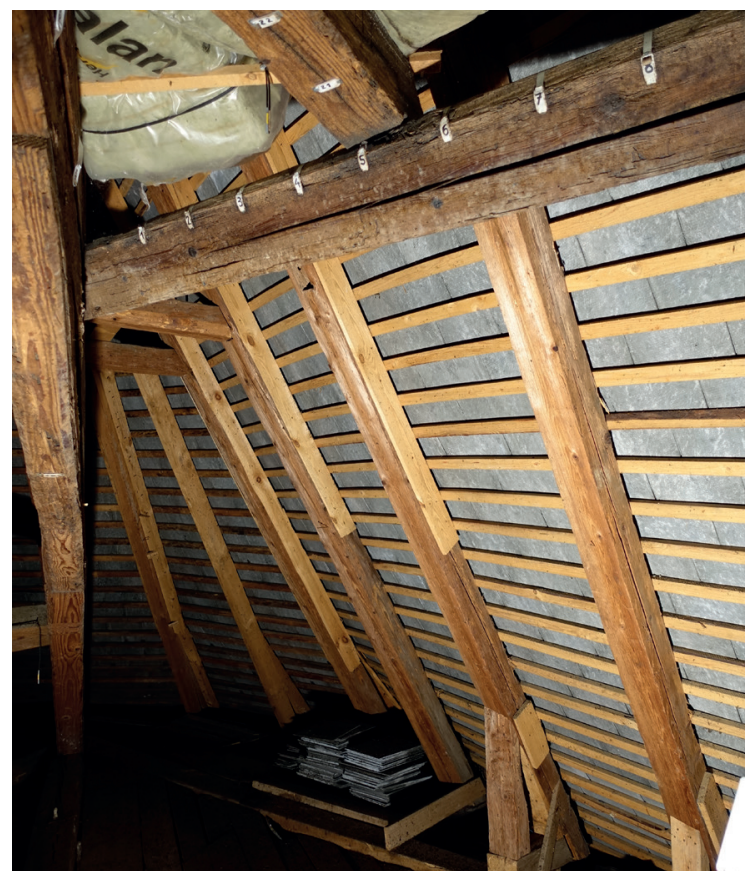

Fig. 1. Horizontal beam in the loft of the Lockenhaus Castle, on which the colony of Myotis emarginatus roosted throughout the study period. 


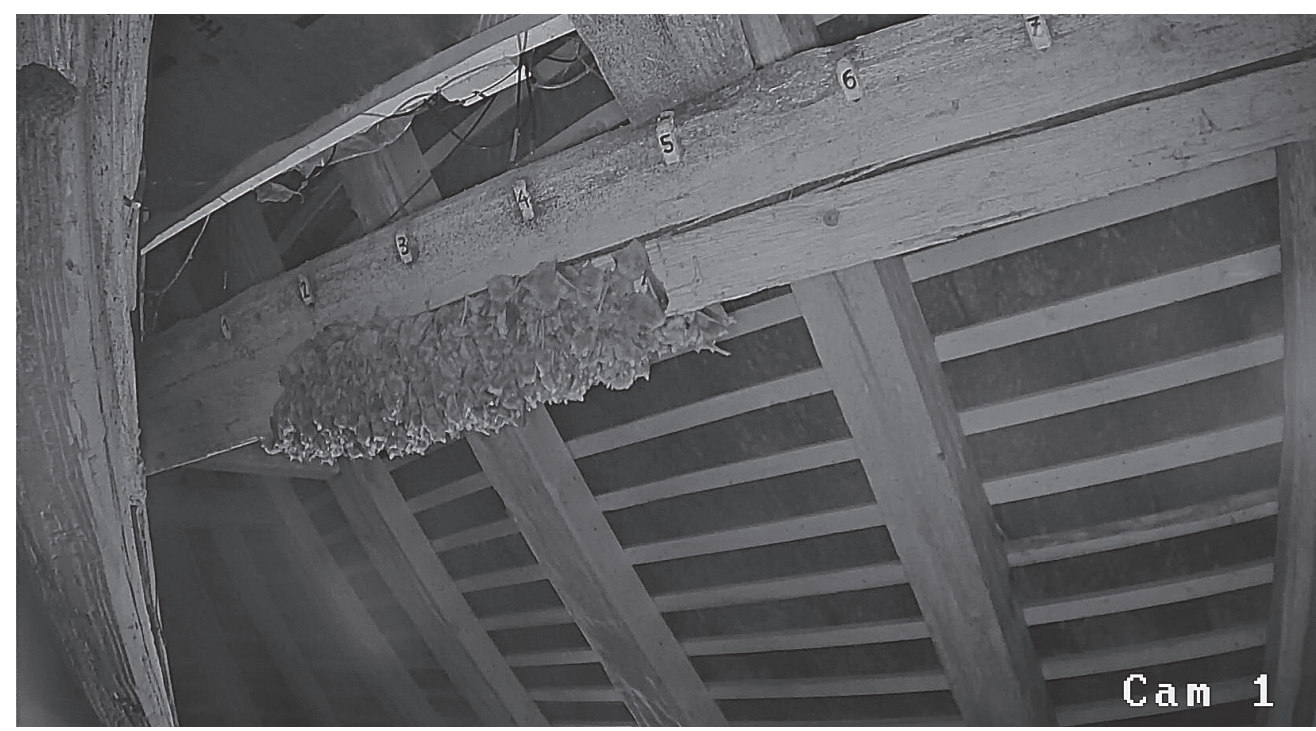

Fig. 2. Cluster roosting on the horizontal beam (photographed on 14 May 2021).

in photographs and infrared films. The maternity colony in the Lockenhaus castle has been continuously monitored by a light barrier and infrared camera since 2011 till to date.

We observed and videotaped the diurnal activities of the colony during pregnancy (four weeks) and lactation (two weeks) at weekly intervals. Over the study period, we conducted six late (11:00-20:00) and six early observational sessions (03:00-10:00) on two successive days (Table 1). The first (7 and 8 May) session took place during a late period of colony formation, twelve days after the initial arrival of the bats in the maternity roost after hibernation. Early observational sessions started approximately one hour after the onset of return flights to the roost and the late observational sessions finished shortly before the emergence flights started.

\section{Methods}

We recorded ambient $\left(T_{a}\right)$ and roost temperatures $\left(T_{r}\right)$ and rainfall events in hourly intervals. The sensor recording $\mathrm{T}_{\mathrm{a}}$ and the rain sensor were positioned at the frame of the access window, that recording $\mathrm{T}_{\mathrm{r}}$ near the beam where the colony roosted.

An infrared light barrier (ChiroTEC Type Liba $16 \mathrm{n}$ ) recording the time and number of females entering and leaving the roost was installed in the frame of the access window of the maternity roost. The numbers of females present in the roost refer to those females that entered the roost in the mornings of observational days. On 22 May the light barriers did not function.

From a room adjacent to the maternity chamber we conducted instantaneous scan sampling of the diurnal activities exhibited by the bats roosting in the cluster (Fig. 2) on the beam by using a remote-controlled Axis 213 PTZ network camera combined with a Visor Tech Recorder PX-1208-675.

The objects of our observations were exclusively adult female bats roosting on the periphery of the cluster. Observations were facilitated by the fact that all colony members roosted together in a single cluster over the whole study period. 


\section{Direct observation of the colony}

We noted (1) diurnal activities exhibited by bats over a period that excluded cluster formation in the morning and cluster disintegration in the evening; (2) number of clusters in the roost; (3) cluster size: (a) small $<12$ individuals; (b) large $>12$ individuals; (4) density of bats roosting on the periphery of the cluster: (a) tight (bats touching each other); (b) loose (bats separated by less than one width of one bat apart); (c) dispersed more than one width of a bat apart (BuRneTt \& August 1981, Winchell \& Kunz 1996).

\section{Instantaneous scan sampling of activity categories}

To obtain data on the percentage of time the colony spent in various activities, instantaneous scan sampling was used. This is a technique in which the observer records an individual's current activity in preselected moments. It is used to obtain data from a larger number of members of a social group, by observing each in turn within a very short time period. The percentage of time a certain activity has been conducted can be estimated from the percent of samples in which this activity has been recorded (AlTMANN 1974).

In accordance with similar previous studies (BuRnETT \& August 1981, Winchell \& KunZ 1993, 1996, Codd et al. 2003, Munoz-Romo 2006, BetTs 2010), we selected the following activity categories, ranked from low to high energy expenditure:

resting roosting motionless, huddling

alert awake, vigilant, stretching, yawning

grooming grooming, licking, gnawing, scratching self

relocating crawling, moving on, out of, or into the cluster, taking flight

During each sampling session, the instantaneous activity states of five individuals constituting a subgroup were ten times sequentially recorded at $2 \mathrm{sec}$ intervals. Each sequence of ten observations constituted a scan and 10 scans constituted a sampling session lasting $1 \mathrm{~min} 40 \mathrm{sec}$. New subgroups were selected at $15 \mathrm{~min}$ intervals and were regularly rotated over the cluster (BURNETT \& AUGUST 1981). Thus, we conducted four scan sampling sessions per hour. If one of the bats of a subgroup disappeared during the scanning, the session was eliminated from subsequent analysis. The data on the five bats exhibiting a certain activity state during each hour were averaged and converted to percentages of activities.

Estimating the ratio between bats numbers on the periphery and in the interior of a cluster

We extrapolated the number of bats roosting on the periphery of the cluster by counting bats on a sampling area covering $17 \%$ of the total periphery. By comparing the resulting number with the number of bats present in the roost recorded by the light barrier on the same day, we found an approximate ratio of 50\% bats roosting in the interior and $50 \%$ roosting on the periphery of the cluster. As the daily clusters of bats were invariably tight during all observational sessions, we applied this ratio during the whole study period.

\section{RESULTS}

Characteristics of the maternity roost

On observational days, the roost climate was rather cool and similar. The mean minimum $\mathrm{T}_{\mathrm{r}}$ across the early observational sessions was $15^{\circ} \mathrm{C}$ and across the late observational sessions $19{ }^{\circ} \mathrm{C}$. During the six early observational sessions, $\mathrm{T}_{\mathrm{r}}$ ranged from $11.5^{\circ} \mathrm{C}$ to $23.5^{\circ} \mathrm{C}$, during the six late observational sessions from $10.5^{\circ} \mathrm{C}$ to $28.0^{\circ} \mathrm{C}$. Due to a severe cold spell occurring in the week 2 (14/15 May) when minimum $\mathrm{T}_{\mathrm{a}}$ dropped to $8.5^{\circ} \mathrm{C}$ (early observational session) and $10.5^{\circ} \mathrm{C}$ (late observational session), $\mathrm{T}_{\mathrm{r}}$ decreased only to $11.5^{\circ} \mathrm{C}$ and $13.5^{\circ} \mathrm{C}$, respectively.

The courses of the ambient and roost temperatures run parallel to each other, whereby the roost temperature was consistently higher than the ambient temperature (Fig. 3). Already at 03:00 in the mornings, roost temperatures were significantly higher than ambient temperatures. On 5 June and 12 June at $02: 30$, the roost temperatures were already $3^{\circ} \mathrm{C}$ and $4{ }^{\circ} \mathrm{C}$, respectively, higher than the ambient temperatures. This indicates that the maternity chamber conserved 
parts of the heat collected during the previous daytime over the whole night, and that $\mathrm{T}_{\mathrm{r}}$ was not influenced by metabolic heat produced by the cluster.

Number of females present in the maternity roost(Fig. 4)

At the first observational session on 7/8 May conducted during early pregnancy, the numbers of females in the roost were high (414 on 7 May), but the cold weather spell in the week 2 diminished them to 104 individuals (14 May). While the numbers stayed at around 300 females during the following two weeks, heavy precipitation reduced again the numbers recorded on
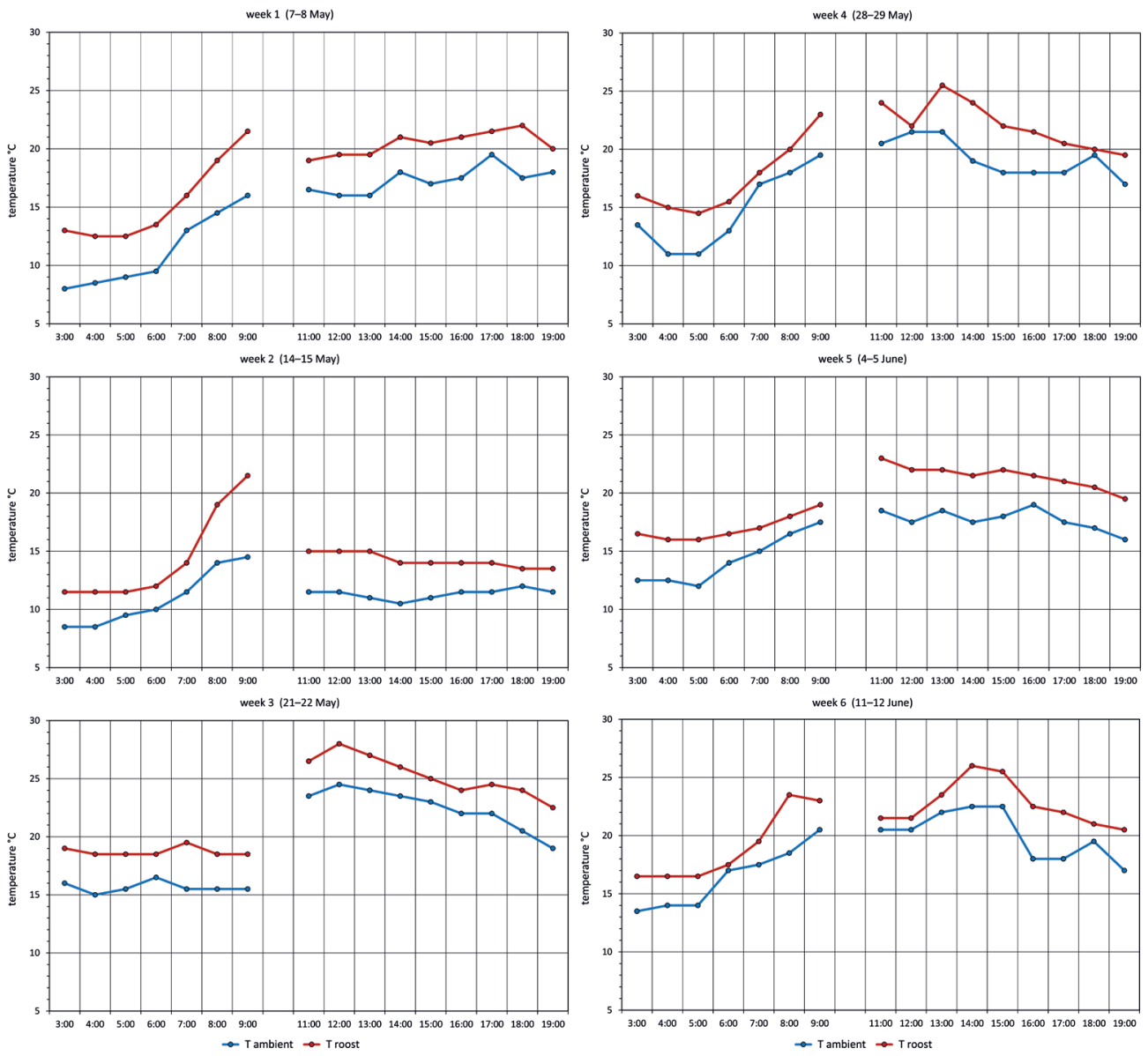

Fig. 3. Hourly ambient $\left(\mathrm{T}_{\mathrm{a}}\right)$ and roost temperatures $\left(\mathrm{T}_{\mathrm{r}}\right)$ recorded during early and late observational sessions in the weeks $1-6$. 


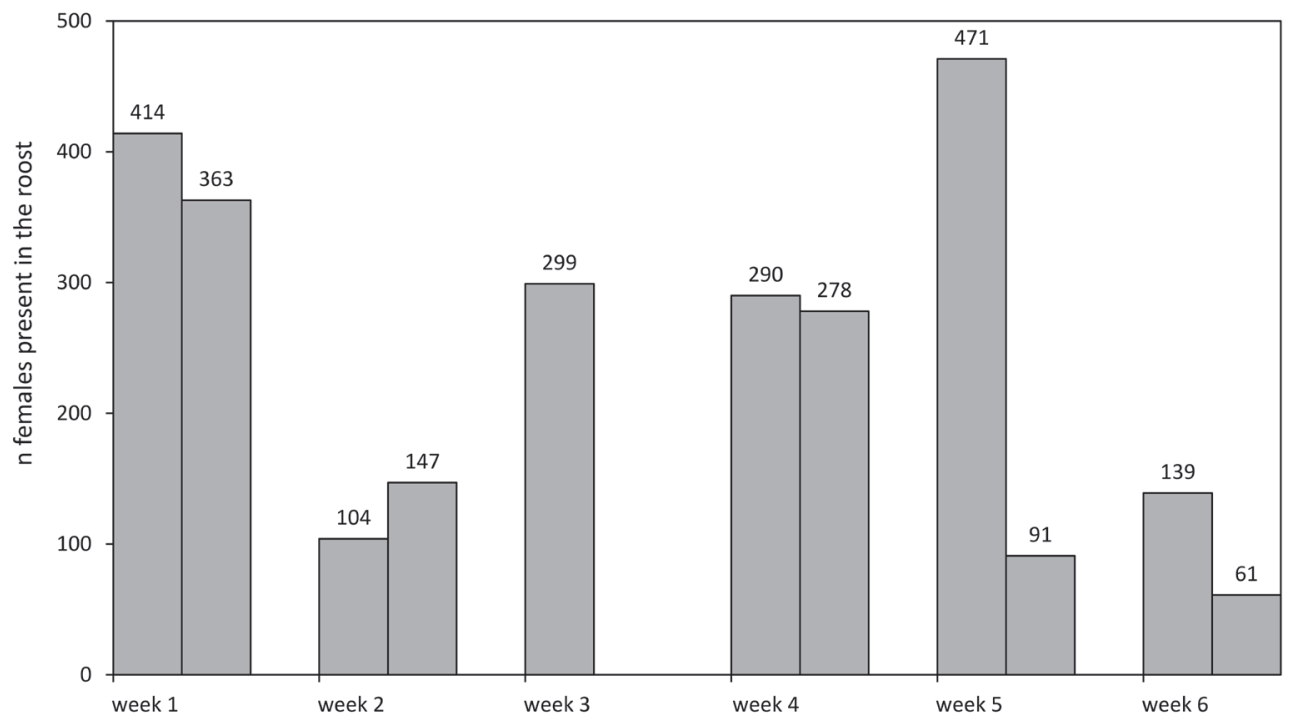

Fig. 4. Numbers of females present in the roost during early (left) and late (right) observational sessions.

4/5 May and 11/12 May during lactation. The decrease from 471 bats emerging from the roost on 4 June to 91 bats returning to the roost on the next morning may have been caused by a heavy rain in the evening before emergence. Two heavy downpours between 17:00 and 18:00 on 11 June might have caused the low number of bats returning to the roost next morning.

Estimating daily and weekly activity budgets

\section{Direct observation of the diurnal behaviours of the roosting colony}

Every morning, the colony formed a single cluster along the same beam. The cluster did not change in size and form until pre-emergence time started. It moved, however, slowly from the left to the right corner of the beam following the sun shining on the roof.

Cluster formation in the morning started around 02:00 with two or three bats landing on the left corner of the beam after entering the roost and establishing bodily contact immediately. Within approximately one hour, all returning individuals landed on or crawled to the huddling group, thus forming one single cluster resembling a bee swarm. Many bats emitted ultrasonic sounds after landing on the cluster before engaging in the struggle for a position within the cluster. Independent of varying roost temperatures and number of roost members, all clusters were invariably large and tight during all observational sessions.

The basic structure of the cluster is a roof-tile-shaped arrangement of several rows of bats which cling to the wooden beam and to each other. The complete cluster is a large, multilayered, three dimensional tightly packed clump of bats clinging around the beam. New arrivals, squeezing vigorously into the cluster not only between the rows but also from the lower and the upper edges of the cluster, destroy the initial arrangement and stick in different positions in the 


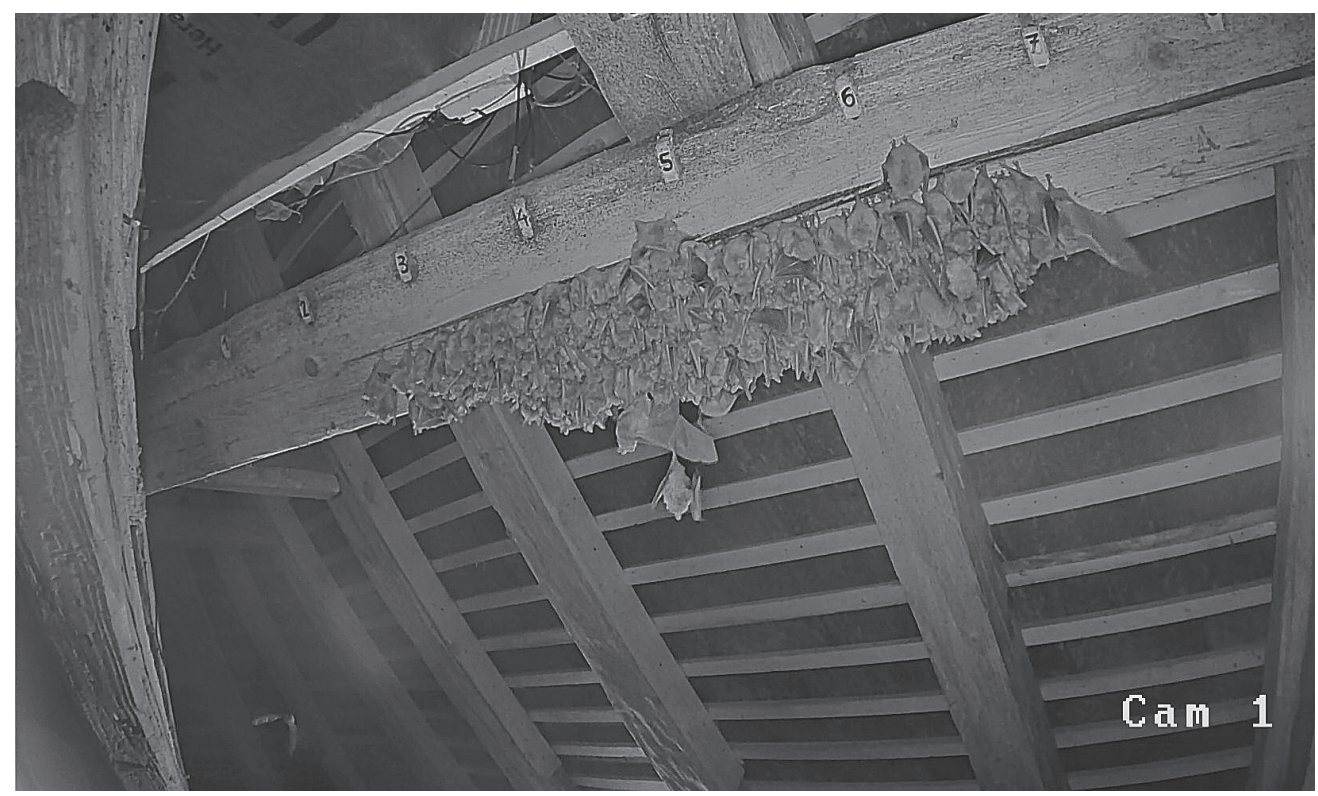

Fig. 5.Two bats pulled out of the interior of the cluster by a bat leaving the cluster (photographed on 14 May 2021).

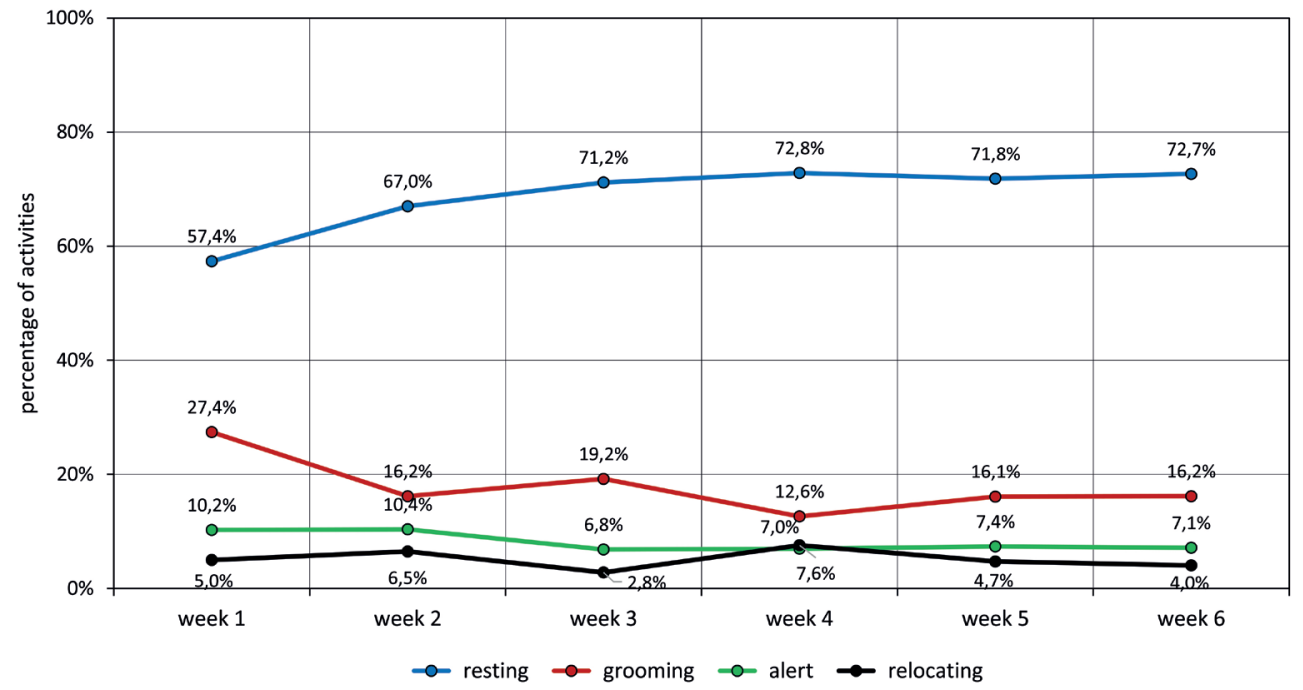

Fig. 6. Mean weekly percentages of time spent in various activities (all hours combined). Data points are connected between weeks as a visual aid only. 
cluster. Already established bats try to prevent intrusions with a different success. During rough jostles we heard bats squeaking but never saw agonistic social interactions. The cluster consists of an interior part and an outer layer, the periphery, each containing about $50 \%$ of the females present in the roost. Significant differences were observed in the amount of time allocated to the various activities between bats located in the interior and on the periphery of the cluster. Bats roosting on the periphery were engaged in resting, grooming, being alert and relocating, whereas the bats located in the interior of the cluster were motionless and presumably sleeping. In tight contact with conspecifics, they were unable to exhibit other activities than resting. We assume that they spent at least about $90-95 \%$ of the whole day-roosting period resting.

Only few single individuals left the interior of the cluster by moving laboriously through the roost mates to the periphery for grooming or urination and defecation which was accomplished either directly on the cluster or during flight. Bats leaving the cluster often pulled out one or two other bats to which it had clung (Fig. 5). Landing again on the cluster, the returning bat tried to occupy a position deep in the interior. Although bats moving out or squeezing in the interior of the cluster grasped ears and parts of the face of peripheral roost mates ruthlessly with their thumb claws, we never observed aggressive behaviour.

Scan sampling of behaviours carried out by bats roosting on the periphery of the cluster We performed six weekly instantaneous scan sampling sessions to quantify the activities exhibited by females roosting on the periphery, each lasting 16 hours. In total we scanned the colony members for 96 hours. We collected data from 156 scan sampling sessions during pregnancy and 128 scan sampling sessions during lactation. In total 384 sessions were performed (Fig. 6).

Resting was the most frequent behaviour exhibited during all observational sessions. The mean weekly percentage of resting increased from $57.4 \%$ in the week 1 and $67 \%$ in the week 2 to a stable level of 71.2-72.8\% during the last two weeks of pregnancy and the two weeks of lactation. The second most important activity was grooming. The mean weekly percentages of grooming decreased from $27 \%$ in the week 1 to $12-16 \%$ in all other weeks with a slight increase in the week $3(19 \%)$. The mean frequency of alertness decreased steadily from $10 \%$ in the weeks 1 and 2 to $7 \%$ and the weekly percentage of relocating animals ranged from $3 \%$ to $8 \%$. It is recognised, however, that bats spend more of their time flying but the scan-sampling technique does not take account of this (CoDD et al. 2003).

An approximate pattern of the hourly amount of time spent in diurnal activities is recognisable over the six early and late observational sessions (Fig. 7). Resting filled most of the time during both observational sessions, but it alternated between high and low levels that were inversely synchronal with bouts of grooming. After arrival at the roost at dawn (03:00-04:00), a high percentage of time was allocated to grooming. After grooming, resting peaked around 05:00 to 06:00. Only in the phase of late lactation (11/12 June, week 6) almost $70 \%$ of time was allocated to resting immediately after return to the roost. During the observational sessions in the weeks $2-6,70-80 \%$ of the time was still allocated to resting one hour before emergence started (around 19:00). Only in the week 1, the percentage of resting was less than $50 \%$ at that time of the day and resting was replaced by grooming.

Reproductive state, number of females present in the roost and roost temperatures appeared to have a little detectable effect on the percentage of time spent in the recorded activities. As shown by relatively high percentages of grooming, alertness and relocation on 7/8 May (week 1), the still ongoing colony formation after the return from hibernation could have created some unrest. Furthermore, we observed a weak influence of bad weather spells on the amount of time spent in various activities. 

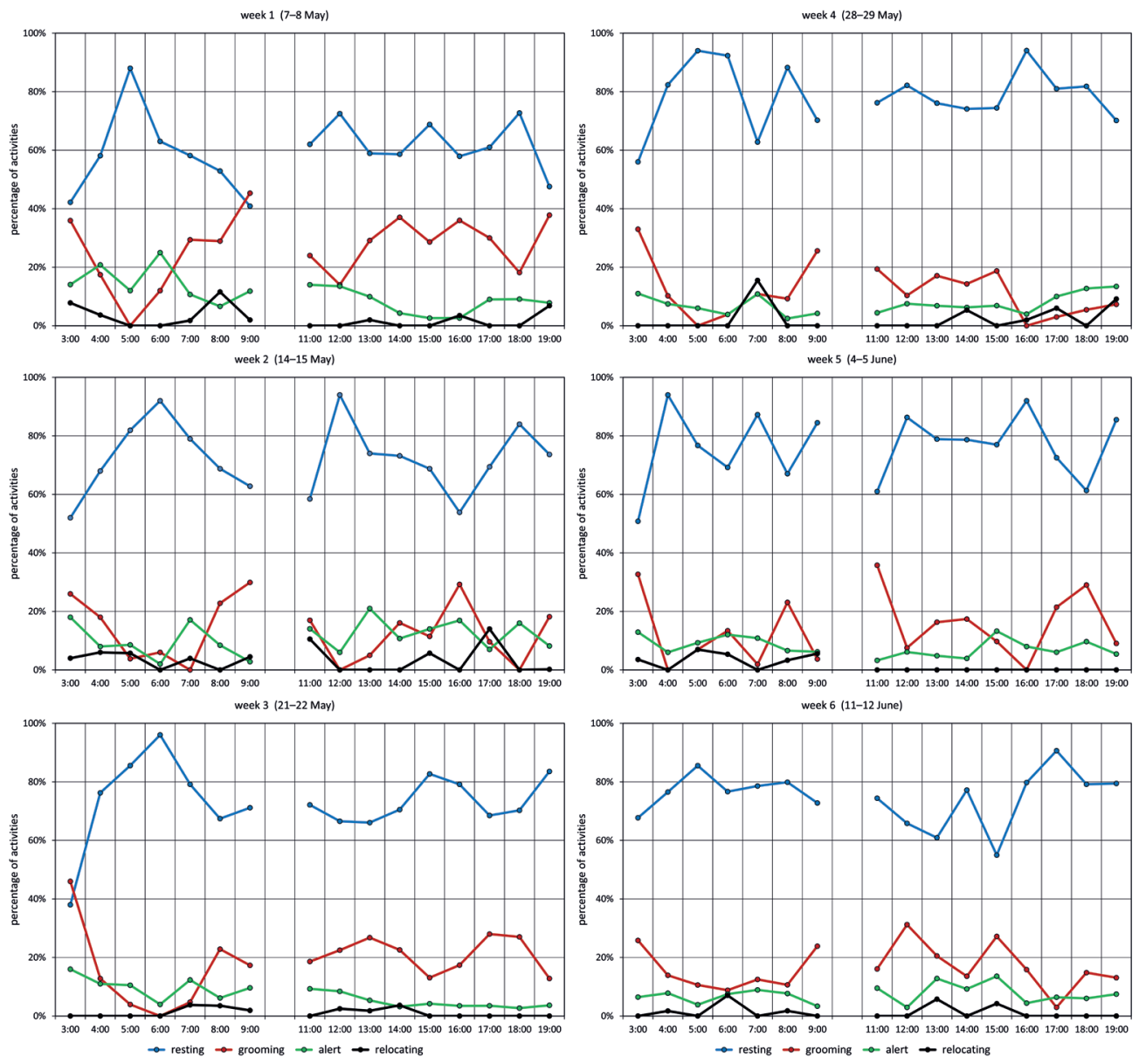

Fig. 7. Hourly patterns of percentages of time allocated to various activities recorded during early and late observational sessions in the weeks 1-6.

\section{DISCUSSION}

During pregnancy and lactation, female bats face high energy demands. Minimising the diurnal energy output allows reproductive bats to maintain high body temperature throughout the breeding period to accelerate the development of both the foetus and young and abbreviate the time spent in the maternity roost. Reproductive Geoffroy's bats minimised energetic expenditure using the following methods:

Energy saving by reproductive Geoffroy's bats was mainly accomplished by social thermoregulation, in particular by huddling. Individuals huddling in a close contact benefit from highly effective insulation and significantly reduced periphery area to the local environment 
leading to crucial reduction of the heat flow and maintenance of higher and more stable body temperature in the cluster (ROVERUD \& CHAPPEL 1991). All bats present in the roost executed huddling in a single tight cluster for 16 hours per day and during the entire seasonal stay in the maternity roost. The separation of females into one half which were fit enough to acquire a place in the interior of the cluster and the other half which roosted on the periphery of the cluster promoted the progress of pregnancy and lactation in the central bats. They enjoyed the benefits of huddling to the full and achieved a maximum of energy conservation by restricting diurnal activities to the estimated $90-95 \%$ of their roosting time to resting which has the least energy cost (BURNETT \& AUGUST 1981). It is probable that the peripheral bats consisted mainly of non-reproductive females (SPITZENBERGER \& WEISS 2020). They allocated on average only $60-73 \%$ of their time to resting.

The energy costs of roosting can also be minimised by selection of an appropriate maternity roost. As the density of the cluster was maintained tight at temperatures ranging from $11.5^{\circ} \mathrm{C}$ to $28.0^{\circ} \mathrm{C}$ it can be assumed that the relatively cool maternity roost fulfilled the requirements of the colony to a high extent. The preference of $M$. emarginatus for cool maternity roosts has been observed since a long time (e. g. Issel \& Issel 1953, KRULl et al. 1991, ZaHN \& HeNATSCH 1998, PIR 2007). By choosing cool roosts, phases of hyperthermia which can occur during high roost temperatures in late lactation and in post-lactation can be minimised, whereas energy loss caused by low temperatures during pregnancy is compensated by intense huddling.

Finally, energy costs caused by engaging in social interactions or aggressive behaviour of roost mates in the cluster were completely omitted.

\section{Acknow ledgements}

We express our gratitude for the hospitality we received from the board of trustees of the Prof. Paul Anton Keller Foundation Burg Lockenhaus and we thank Karl KugELSCHAFTER for technical support.

\section{REFERENCES}

Altmann J., 1974: Observational study of behavior: sampling methods. Behaviour, 49: 227-267.

Bauerová Z., 1986: Contribution to the trophic bionomics of Myotis emarginatus. Folia Zoologica, 35 : 305-310.

Beck A., 1995: Fecal analyses of European bat species. Myotis, 32-33: 109-119.

Benda P. \& HanÁK V., 2003: Present state of distribution of the Geoffroy's bat (Myotis emarginatus) in Bohemia (Czech Republic). Vespertilio 7: 71-86.

BetTs B. J., 2010: Activity budgets of Townsend's big-eared bats at a maternity colony in northeastern Oregon. Northwestern Naturalist, 91: 13-22.

Boyles J. G., Storm J. J. \& Brack V., 2008: Thermal benefits of clustering during hibernation: a field test of competing hypotheses on Myotis sodalis. Functional Ecology, 22: 632-636.

Brinkmann R., Hensle E. \& STECK C., 2001: Artenschutzprojekt Wimperfledermaus. Untersuchungen zu Quartieren und Jagdhabitaten der Freiburger Wimperfledermauskolonie als Grundlage für Schutz- und Entwicklungsmaßnahmen. Landesanstalt für Umweltschutz, Freiburg \& Karlsruhe, 44 pp.

Burnett C. D. \& August P. V., 1981: Time and energy budgets for dayroosting in a maternity colony of Myotis lucifugus. Journal of Mammalogy, 62: 758-766.

CODD J. R., SANDERSON K. J. \& BRANFORD A. J., 2003: Roosting activity budget of the southern bent-wing bat (Miniopterus schreibersii bassanii). Australian Journal of Zoology, 51: 307-316.

GAISLER J., 1971: Zur Ökologie von Myotis emarginatus in Mitteleuropa. Decheniana Beihefte, 18: $71-82$. 
Gilbert C., McCafferty D., Le Maho Y., Martrette J. M., Giroud S., Blanc S. \& Ancel A., 2010: One for all and all for one: the energetic benefits of huddling in endotherms. Biological Reviews of the Cambridge Philosophical Society, 85: 545-556.

Goiti U., Aihartza J., Guiu M., Salsamendi E., Almenar D., Napal M. \& Garin I., 2011: Geoffroy's bat, Myotis emarginatus, preys preferentially on spiders in multistratified dense habitats: a study of foraging bats in the Mediterranean. Folia Zoologica, 60: 17-24.

Harrison D. L. \& Bates P. J. J., 1991: The Mammals of Arabia. Second Edition. Harrison Zoological Museum, Sevenoaks, 354 pp.

Hayes J. P., Speakman J. R. \& Racey P. A., 1992: The contributions of local heating and reducing exposed surface area to the energetic benefits of huddling by short-tailed field voles (Microtus agrestis). Physiological Zoology, 65: 742-762.

HORAČEK D. \& JóžA M., 2011: Rhinolophus hipposideros and Myotis emarginatus in northern Bohemia. Vespertilio, 15: 89-99.

Issel B. \& Issel W., 1953: Zur Verbreitung und Lebensweise der Gewimperten Fledermaus, Myotis emarginatus (Geoffroy, 1806). Säugetierkundliche Mitteilungen, 1: 145-148.

Kervyn T., Godin M.-C., Jocque R., Grootaert P. \& Libois R., 2012: Web-building spiders and bloodfeeding flies as prey of the notch-eared bat (Myotis emarginatus). Belgian Journal of Zoology, 142: 59-67.

Krull D., Schumm A., MetZner W. \& Neuweiler G., 1991: Foraging areas and foraging behavior in the notcheared bat, Myotis emarginatus (Vespertilionidae). Behavioral Ecology and Sociobiology, 28: 247-253.

Kugelschafter K. \& Hensle E., 2017: The duration of hibernation of indigenous bat species - results of multiannual field research. P.: 80. In: Bärmann E., Begall S., Benke H., Dammann P., Giere P., Hackländer K., Kert G., Langner C., Schönherr H., Ulrich R. G., Zachos F. \& Bussmann B. M. (eds.): 91st Annual Meeting. Deutsche Gesellschaft für Säugetierkunde (DGS). Friedrich-Loeffler-Institut \& University Greifswald, Greifswald, 168 pp.

Munoz-Romo M., 2006: Ethogram and diurnal activities of a colony of Artibeus lituratus (Phyllostomidae: Stenodermatidae). Acta Chiropterologica, 8: 231-238.

PIR J. P., 2007: On the roosting ecology of Geoffroy's bat (Myotis emarginatus, Geoffroy 1806) in western Europe. Hystrix (n. s.), Supplement: 217.

RACEY P., 1973: Environmental factors affecting the length of gestation in heterothermic bats. Journal of Reproduction and Fertility, Supplement 19: 175-189.

Richarz K., KRUll D. \& SChumm A., 1989: Quartieransprüche und Quartierverhalten einer mitteleuropäischen Wochenstubenkolonie von Myotis emarginatus (Geoffroy 1806) im Rosenheimer Becken, Oberbayern, mit Hinweisen zu den derzeit bekannten Wochenstubenquartieren dieser Art in der BRD. Myotis, 27: 111-130.

Roverud R. C. \&. Chappell M. A., 1991: Energetic and thermoregulatory aspects of clustering behavior in the Neotropical bat Noctilio albiventris. Physiological Zoology, 64: 1527-1541.

RuEDi M. \& MAYER F., 2001: Molecular systematics of bats of the genus Myotis (Vespertilionidae) suggests deterministic ecomorphological convergences. Molecular Phylogenetics and Evolution, 21: 436-448.

Ruedi M., Stadelmann B., Gager Y., Douzery E. J. P., Francis C. M., Lin L.-K., Guillén-Servent A. \& Ciвois A., 2013: Molecular phylogenetic reconstructions identify East Asia as the cradle for the evolution of the cosmopolitan genus Myotis (Mammalia, Chiroptera). Molecular Phylogenetics and Evolution, 69: 437-449.

SPITZENBERGER F. \& Weiss E., 2017: Conspicuous body markings in infant Myotis emarginatus. Lynx, n. s., 48: 211-214.

Spitzenberger F. \& Weiss E., 2020: Time keeping in female Myotis emarginatus during reproduction (Chiroptera: Vespertilionidae). Lynx, n. s., 51: 131-145.

Steck C. \& Brinkmann R., 2006: The trophic niche of the Geoffroy's bat (Myotis emarginatus) in south-western Germany. Acta Chiropterologica, 8: 445-450.

Trune R. \& Slobodchiкoff C. N., 1967: Social effects of roosting on the metabolism of the pallid bat (Antrozous pallidus). Journal of Mammalogy, 57: 656-663. 
Voigt C. C. \& Cruz-Neto A., 2009: Energetic analysis of bats. Ecological and Behavioral methods for the study of bats. Pp.: 623-645. In: KunZ T. \& Parsons S. (eds.): Ecological and Behavioral Metods for the Study of Bats. The John Hopkins University Press, Baltimore, $901 \mathrm{pp}$.

Wilde C. J., Knight C. H. \& Racey P. A., 1999: Influence of torpor on milk protein composition and secretion in lactating bats. Journal of Exprimental Zoology, 284: 35-41.

Winchell J. M. \& KunZ T. H., 1993: Sampling protocols for estimating time budgets of roosting bats. Canadian Journal of Zoology, 71: 2244-2249.

Winchell J. M. \& KunZ T. H., 1996: Day roosting activity budgets of the eastern pipistrelle bat, Pipistrellus flavus (Chiroptera, Vespertilionidae). Canadian Journal of Zoology, 74: 431-444.

ZaHn A. \& HenATSCH B., 1998: Bevorzugt Myotis emarginatus kühlere Wochenstubenquartiere als Myotis myotis? Zeitschrift für Sängetierkunde, 63: 26-31.

Zahn A., Bauer S., Kriner E. \& Holzhaider J., 2010: Foraging habitats of Myotis emarginatus in Central Europe. European Journal of Wildllife Research, 56: 395-400. 